Article

\title{
A Breakthrough Application of a Cross-Linked Polystyrene Anion-Exchange Membrane for a Hydrogencarbonate Ion-Selective Electrode
}

\author{
Sylwia Dabrowska, Jan Migdalski and Andrzej Lewenstam *ii \\ Faculty of Materials Science and Ceramics, AGH-University of Science and Technology, Mickiewicza 30, \\ 30-059 Krakow, Poland; sd.dabrowska@gmail.com (S.D.); migdal@agh.edu.pl (J.M.) \\ * Correspondence: andrzej.lewenstam@gmail.com
}

Received: 15 February 2019; Accepted: 8 March 2019; Published: 13 March 2019

check for updates

\begin{abstract}
Polystyrene cross-linked with divinylbenzene and functionalized by a quaternary ammonium cation anion site is used as the membrane of a hydrogencarbonate (i.e., bicarbonate) ion-selective electrode. The polystyrene matrix membrane improves the selectivity towards interfering lipophilic ions in comparison to previously described polyvinyl chloride membranes. The reason for this behaviour is sought in coupled ion-exchange and pore-diffusion processes in the membrane and the resulting kinetic discrimination of interfering ions. The electrode is successfully used for determination of bicarbonates in mineral drinking waters. The simplex method is employed to refine the analytical outcome.
\end{abstract}

Keywords: bicarbonate ion-selective electrode; polystyrene matrix; anion exchange membrane; direct potentiometry; simplex optimization

\section{Introduction}

Hydrogencarbonate (bicarbonate) is the only anion which is not directly measured by ion-selective electrodes (ISEs), even at the $\mathrm{mmol} \mathrm{L}^{-1}$ concentrations found in blood [1]. Direct sensitivity to bicarbonate ions has been occasionally reported previously, but it has finally been ascribed to hydroxyl [2] ions or carbonate ions [3-6] and not to bicarbonates. The fact is that, so far, the determination of bicarbonates is possible only by indirect methods, e.g., $[3,7,8]$.

The primary reason for the difficulty in designing a bicarbonate-sensitive ion-selective electrode is in the native properties of the bicarbonate anion, i.e., its hydration energy and ionic potential. These properties both determine its place in the Hoffmeister series which is close to that of chlorides. This makes finding a membrane with sufficient selectivity, especially towards chloride ions frequently present in real samples, extremely difficult. Additionally, the direct influence of hydrogen ions and pH-dependent carbonate ions impose a severe challenge.

Another drawback stems from the routines used in ISE membrane technology. Typically, the polymer applied to support electroactive ISE membrane components is a plasticized polyvinyl chloride (PVC) [9]. Although its suitability is well proved, ongoing research aims to take advantage of other polymers to reduce or eliminate plasticizer leaching, to improve biocompatibility, to improve sensor performance, its response time, selectivity, and detection limit. For these reasons, many other polymers have been tested, namely viscose cellulose, silicone rubber, cellulose acetate, acrylic polymers and polyurethanes [4,6,10-15].

In our previous work [16], we proposed a bicarbonate electrode based on a PVC membrane containing quaternary ammonium bicarbonate as ion exchanger. It was shown that the change of plasticizer or even its elimination from the PVC membrane caused only a slight improvement in 
the selectivity. This report presents an application of a divinylbenzene cross-linked polystyrene anion ion-exchanger functionalized by quaternary ammonium bicarbonate as a membrane in an ion-selective bicarbonate electrode. We demonstrate that with use of such a membrane, a bicarbonate ISE with substantially improved analytical properties can be obtained. Although polystyrene anionic membranes have recently been used in fuel cells and electrodialysis $[17,18]$, to the best of our knowledge the functionalization and application of this membrane type for a bicarbonate ISE is reported here for the first time.

\section{Materials and Methods}

\subsection{Reagents}

All the compounds used were purchased from Avantor Performance Materials (Gliwice, Poland) or Sigma-Aldrich (Darmstadt, Germany). Distilled and deionized water was used for preparation of the aqueous solutions. Natural mineral healing waters: Franciszek and Jozef (Wysowa, Poland), Jan and Slotwinka (Krynica Zdroj, Poland), Donat Mg (Rogaska Slatina, Slovenia) and mineral waters: Cisowianka (Naleczow, Poland), Kryniczanka (Krynica Zdroj, Poland), Staropolanka (Polanica Zdroj, Poland) were used. These waters were chosen because of the different total content of mineral electrolytes. Moreover, some of these waters contain relatively high concentrations of chloride ions and other interferents $\left(\mathrm{SO}_{4}{ }^{2-}, \mathrm{Br}^{-}\right)$. Their composition specified by the manufacturer is shown in Table 1 . In order to test potentiometric ion-selective electrodes with a cross-linked polystyrene anion-exchange membrane for the direct determination of bicarbonate ions, several samples (Samples 1-6, see Table 1) with a known concentration of bicarbonate and chloride ions were used.

Table 1. Composition of mineral healing waters and mineral water samples from labels of the bottles.

\begin{tabular}{|c|c|c|c|c|c|}
\hline \multicolumn{6}{|c|}{ Mineral Water } \\
\hline Water Sample & $\begin{array}{c}\text { Total mineral } \\
\text { content }\left[\mathrm{mg} \mathrm{L}^{-1}\right]\end{array}$ & $\begin{array}{c}\mathrm{HCO}_{3}^{-} \\
{\left[\mathrm{mmol} \mathrm{L}^{-1}\right]}\end{array}$ & $\begin{array}{c}\mathrm{Cl}^{-} \\
{\left[\mathrm{mmol} \mathrm{L}^{-1}\right]}\end{array}$ & $\begin{array}{c}\mathrm{Br}^{-} \\
{\left[\mathrm{mmol} \mathrm{L}^{-1}\right]}\end{array}$ & $\begin{array}{c}\mathrm{SO}_{4}{ }^{2-} \\
{\left[\mathrm{mmol} \mathrm{L}^{-1}\right]}\end{array}$ \\
\hline Jan & 821.5 & 8.6 & 1.2 & - & 0.52 \\
\hline Jozef & 2276.0 & 21.5 & 7.5 & - & - \\
\hline Slotwinka & 3931.2 & 49.1 & 0.45 & - & 0.04 \\
\hline Donat Mg & 13055.0 & 121.9 & 1.7 & - & 21.4 \\
\hline Franciszek & 16030.0 & 139.0 & 65.0 & 11.2 & 11.2 \\
\hline Cisowianka & 742.0 & 8.8 & - & - & - \\
\hline Staropolanka & 800.0 & 9.3 & 0.19 & - & 0.33 \\
\hline Kryniczanka & 2094.9 & 25.5 & 0.27 & - & 0.03 \\
\hline \multicolumn{6}{|c|}{ Samples } \\
\hline & \multicolumn{2}{|c|}{$\begin{array}{c}\mathrm{NaHCO}_{3} \\
{\left[\mathrm{mmol} \mathrm{L}^{-1}\right]}\end{array}$} & \multicolumn{3}{|c|}{$\begin{array}{c}\mathrm{NaCl} \\
{\left[\mathrm{mmol} \mathrm{L}^{-1}\right]}\end{array}$} \\
\hline 1 & \multicolumn{2}{|c|}{100} & \multicolumn{3}{|c|}{10} \\
\hline 2 & \multicolumn{2}{|c|}{50} & \multicolumn{3}{|c|}{10} \\
\hline 3 & \multicolumn{2}{|l|}{25} & \multicolumn{3}{|c|}{10} \\
\hline 4 & \multicolumn{2}{|c|}{100} & \multicolumn{3}{|c|}{100} \\
\hline 5 & \multicolumn{2}{|l|}{50} & \multicolumn{3}{|c|}{100} \\
\hline 6 & \multicolumn{2}{|c|}{25} & \multicolumn{3}{|c|}{100} \\
\hline
\end{tabular}

\subsection{Ion-Exchanger Membrane}

A polystyrene anion-exchange membrane cross-linked with divinylbenzene and functionalized with quaternary ammonium chloride salt (AMI-7001S) was obtained from Membranes International 
Inc. (Ringwood, NJ, USA). The membrane thickness was $0.45 \mathrm{~mm}$, total anion-exchange capacity $1.3 \mathrm{meq} \cdot \mathrm{g}^{-1}$ and electrical resistance $<40 \Omega \cdot \mathrm{cm}^{-2}$.

\subsection{Hydrogencarbonate (Bicarbonate) Ion-Selective Electrode}

A diaphragm sheet (AMI-7001S, Membranes International Inc., Ringwood, NJ, USA) was used as a primary material to cut out the membrane rings of $7 \mathrm{~mm}$ diameter which were then placed in the electrode body of an IS-561 device (Philips, Sigma-Aldrich, Darmstadt, Germany). $10^{-1} \mathrm{~mol} \mathrm{~L}^{-1}$ $\mathrm{NaHCO}_{3}$ and $10^{-4} \mathrm{~mol} \mathrm{~L}^{-1} \mathrm{NaCl}$ solution and silver chloride electrode form the internal contact. Before potentiometric measurements, the electrodes were conditioned (soaked) for at least $24 \mathrm{~h}$ in $10^{-1} \mathrm{~mol} \mathrm{~L}^{-1} \mathrm{NaHCO}_{3}$ solution. During soaking, the solution was changed several times to ensure complete filling of the disposable cationic sites by hydrogencarbonate ions [16].

\subsection{Potentiometric Measurements}

Potentiometric measurements were carried out with a multichannel potentiometric meter, with an input resistance higher than $10^{13} \Omega$ and an input current at the level $10^{-15} \mathrm{~A}$, coupled with computer data collection and recording. The reference electrode was a double-junction reference $\mathrm{Ag} / \mathrm{AgCl}$ electrode (Radiometer REF251, Loveland, CO, USA) with an external electrolyte $10^{-1} \mathrm{~mol} \mathrm{~L}^{-1} \mathrm{~K}_{2} \mathrm{SO}_{4}$. Potentiometric measurements were performed at room temperature $\left(23-25^{\circ} \mathrm{C}\right)$.

\subsection{Measuring Procedure}

The selectivity coefficient was determined by two methods for the following interfering ions: $\mathrm{SO}_{4}{ }^{2-}\left(\mathrm{Na}_{2} \mathrm{SO}_{4}\right), \mathrm{Cl}^{-}(\mathrm{NaCl}), \mathrm{Br}^{-}(\mathrm{NaBr})$. In both methods, the semi-empirical Nikolskii-Eisenman equation:

$$
E=E^{0}+S \log \left(a_{i}+\sum K_{i, j}^{p o t} \cdot a_{j}^{z_{i} / z_{j}}\right)
$$

is used for calculation of the selectivity coefficient $K_{i, j}^{\text {pot }}$ where $i$ denotes a primary (main) ion and $j$ an interfering ion. Prior to determination of the selectivity coefficients, the electrodes were conditioned overnight in $0.1 \mathrm{~mol} \mathrm{~L}^{-1} \mathrm{NaHCO}_{3}$ solution. The selectivity coefficients were determined by the separate solution method according to the following formula, using the experimental slope:

$$
\log K_{\mathrm{HCO}_{3}^{-}, j}^{p o t}=\left(E_{j}^{0}-E_{\mathrm{HCO}_{3}^{-}}^{0}\right) / S_{\mathrm{HCO}_{3}^{-}}
$$

where $\log \mathrm{K}_{\mathrm{HCO}_{3}^{-}, j}^{\text {pot }}$ is the logarithm of selectivity coefficient, $\mathrm{S}_{\mathrm{HCO}_{3}^{-}}$is the slope of the bicarbonate electrode, and $E_{j}^{0}$ and $E_{\mathrm{HCO}_{3}^{-}}^{0}$ are the values obtained by the extrapolated calibration curves for various anions and hydrogencarbonate to $\log \mathrm{a}=0$.

In the separate solution method (SSM), the changes in the potentials were measured in $\mathrm{NaHCO}_{3}$ solution and then in the interferent solution within concentrations of $10^{-5}-10^{-1} \mathrm{~mol} \mathrm{~L}^{-1}$. On the other hand, in the fixed primary ion method (FPM), the potentials were measured in the solutions with constant activity of $\mathrm{NaHCO}_{3}\left(\mathrm{NaHCO}_{3}\right.$ concentration was $\left.25 \mathrm{mmol} \mathrm{L}^{-1}\right)$ and varying interferent activities. The selectivity coefficient, $\mathrm{K}_{\mathrm{HCO}_{3}^{-}, j^{\prime}}$ was calculated from the following equation:

$$
K_{\mathrm{HCO}_{3}^{-}, j}^{\text {pot }}=a_{\mathrm{HCO}_{3}^{-}} / a_{j}^{1 / z_{j}}
$$

where $a$ is the ion activity and $z_{j}$ is the electrical charge of the interfering ion. The activity of the individual ions was calculated according to the Debye-Hückel equation.

\subsection{Energy Dispersive X-ray Spectroscopy (EDS) and X-ray Photoelectron Spectroscopy (XPS)}

The chemical composition of the membrane is monitored by Energy Dispersive X-ray Spectroscopy, EDS (LINK ISIS 300, Oxford Instruments, UK) and X-ray photoelectron spectroscopy, XPS (PHI 5000 
VersaProbe, Physical Electronics, Inc., Chanhassen, MN, USA) with monochromatized Mg K $\alpha$ line with energy $1253.6 \mathrm{eV}$ ). Studies were carried out with the membranes conditioned in $10^{-1} \mathrm{~mol} \mathrm{~L}^{-1}$ $\mathrm{NaHCO}_{3}$ and non-conditioned membranes.

\section{Results and Discussion}

\subsection{Inducing Sensitivity towards Bicarbonates}

The main idea of inducing bicarbonate sensitivity is to use an ion-exchanger membrane containing the sites so as to electrostatically attract anions. In our case, the sites are positively charged quaternary ammonium ions $\left(\mathrm{R}_{4} \mathrm{~N}^{+}\right)$dispersed in the polymer bulk as well as on the surfaces of the pores inside the polymer membrane, charge-balanced by $\mathrm{Cl}^{-}$ions. Our aim was to load the sites to the largest possible degree by the counter ions of our interest, bicarbonate ions $\left(\mathrm{HCO}_{3}{ }^{-}\right)$. This was done by prolonged soaking the native anion-exchanger membrane in $0.1 \mathrm{~mol} \mathrm{~L}^{-1}$ solution of $\mathrm{NaHCO}_{3}$, with the resulting ion-exchange:

$$
\mathrm{R}_{4} \mathrm{~N}^{+} \mathrm{Cl}^{-}(m)+\mathrm{HCO}_{3}^{-}(s) \rightleftarrows \mathrm{R}_{4} \mathrm{~N}^{+} \mathrm{HCO}_{3}^{-}(m)+\mathrm{Cl}^{-}(s)
$$

The exchange of native chlorides for bicarbonates is a necessary condition for making a membrane potentiometrically sensitive to that "main" ion, characterized by a slope typical for monovalent anions, where a theoretical value is: $59.2 \mathrm{mV}$ at $25^{\circ} \mathrm{C}$.

SEM/EDS analysis was conducted to investigate the change in the chemical composition of the membranes and the extent of substitution of the native chlorides to invited bicarbonates. Measurements were performed for a non-conditioned polystyrene membrane (Figure 1a) and for this membrane after conditioning in $10^{-1} \mathrm{~mol} \mathrm{~L}^{-1} \mathrm{NaHCO}_{3}$ (Figure 1b). The EDS results indicate apparent replacement of chloride ions from lipophilic sites in the polystyrene membrane.

a)

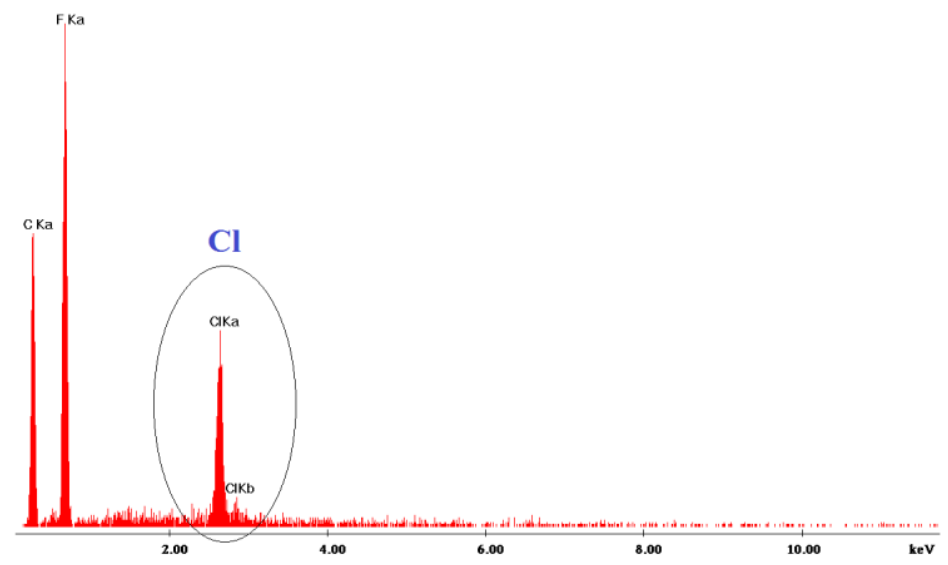

b)

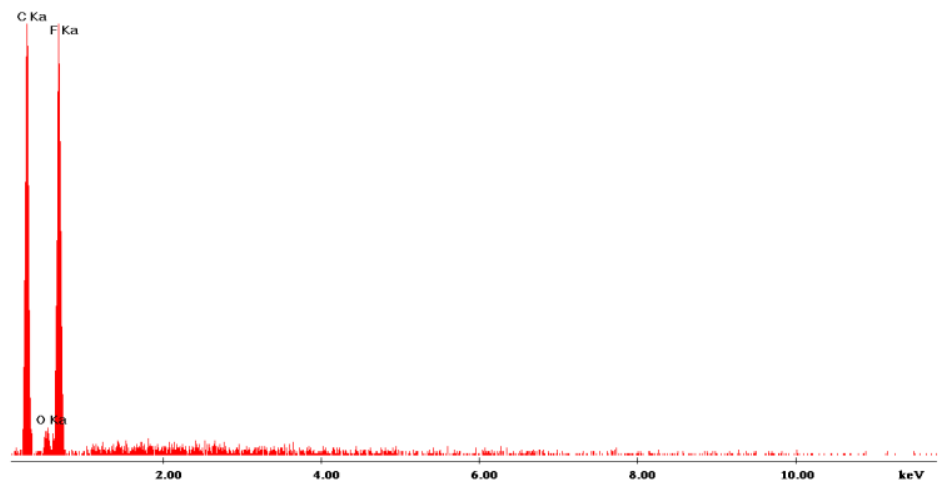

Figure 1. EDS spectra of the polystyrene membranes, (a) non-conditioned, (b) conditioned membrane in $0.1 \mathrm{~mol} \mathrm{~L}^{-1} \mathrm{NaHCO}_{3}$. 


\subsection{Sensitivity of the Sensor}

Presence of the main ion alone might not be sufficient for obtaining a bicarbonate ISE, because of the influence of the interfering ions which can also contribute to the ISE response by ion exchange. One great challenge comes naturally from carbonates. Since the soaking is done with the water, and the water saturates the membrane pores, we must consider that carbon dioxide exists in three different inorganic forms, bicarbonate $\left(\mathrm{HCO}_{3}{ }^{-}\right)$, carbonate ions $\left(\mathrm{CO}_{3}{ }^{2-}\right)$ and carbon dioxide $\left(\mathrm{CO}_{2}\right)$, which appear depending on the $\mathrm{pH}$ (Figure 2).

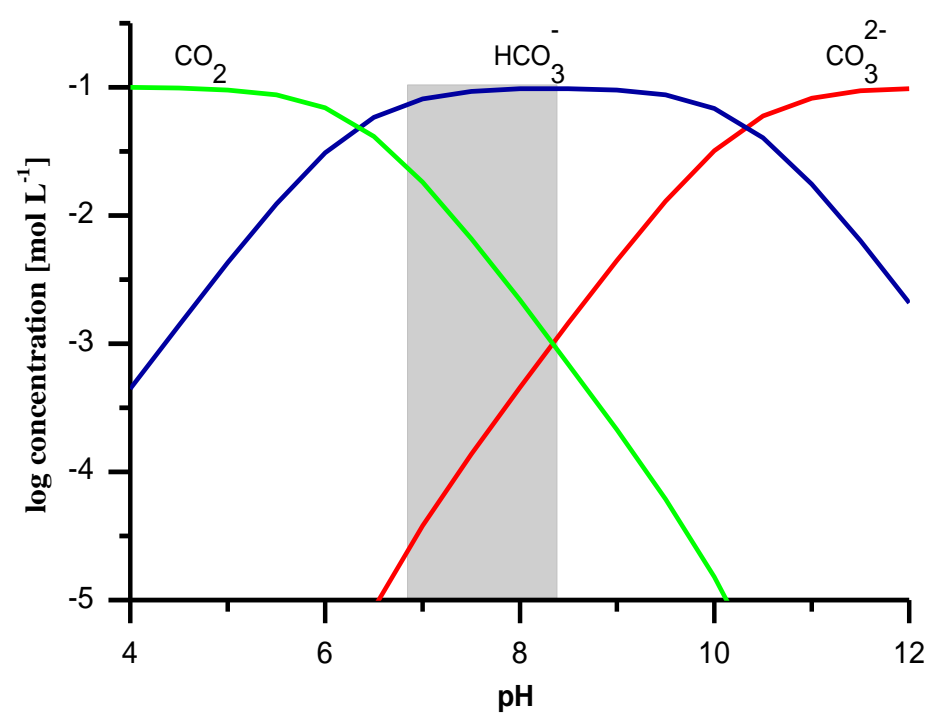

Figure 2. Forms of $\mathrm{CO}_{2}$ as a function of $\mathrm{pH}$; total concentration of $\mathrm{CO}_{2} 0.1 \mathrm{~mol} \mathrm{~L}-1$; temperature $25^{\circ} \mathrm{C}$.

The total carbonate species are related by the following equilibria:

$$
\mathrm{CO}_{2}(\mathrm{aq})+\mathrm{H}_{2} \mathrm{O} \stackrel{K_{1}}{\rightleftarrows} \mathrm{HCO}_{3}^{-}+\mathrm{H}^{+} \stackrel{K_{2}}{\rightleftarrows} \mathrm{CO}_{3}^{2-}+2 \mathrm{H}^{+}
$$

Chemical equilibria among these species in water are described by the constants which are related to activity:

$$
\begin{gathered}
K_{1}=\frac{a_{\mathrm{HCO}_{3}^{-}} a_{\mathrm{H}^{+}}}{a_{\mathrm{CO}_{2}}}=4.5 \cdot 10^{-7} \\
K_{2}=\frac{a_{\mathrm{CO}_{3}^{2-}} a_{\mathrm{H}^{+}}}{a_{\mathrm{HCO}_{3}^{-}}}=4.7 \cdot 10^{-11}
\end{gathered}
$$

During soaking in $0.1 \mathrm{~mol} \mathrm{~L}^{-1} \mathrm{NaHCO}_{3}$ in which the $\mathrm{pH}$ is 8.3 , the bicarbonates are dominant but the concentration of carbonates in this solution is $0.001 \mathrm{~mol} \mathrm{~L}^{-1}$ and their influence should be considered. The carbonate ion may enter the membrane through the reaction:

$$
2 \mathrm{R}_{4} \mathrm{~N}^{+} \mathrm{Cl}^{-}(m)+\mathrm{CO}_{3}^{2-}(s) \rightleftarrows\left(R_{4} \mathrm{~N}^{+}\right)_{2} \mathrm{CO}_{3}^{2-}(m)+2 \mathrm{Cl}^{-}(s)
$$

This process can affect the sensitivity of the received ion-selective electrodes and would be manifested by a decrease of the apparent slope, and in an extreme case to that characteristic for divalent ions, i.e., $29.6 \mathrm{mV}$.

The presence of bicarbonates and carbonates in conditioned membranes was inspected by XPS. The soaking influenced $\mathrm{C}$ (1s) core level around $287 \mathrm{eV}$. After conditioned in $\mathrm{NaHCO}_{3}$ additional peak appear at $\sim 286.95 \mathrm{eV}$ confirming as shown in Figure 3. Interestingly, these peaks are escribed to $\mathrm{C}-\mathrm{O}-\mathrm{C}$ representing bicarbonates bonds (Figure $3 \mathrm{~b}$ ). Deconvolution of the high-resolution spectra of $\mathrm{O}$ (1s) peaks shows additional peaks at $\sim 531.40 \mathrm{eV}$ related to $\mathrm{C}-\mathrm{O}-\mathrm{H}$ and at $\sim 530.65 \mathrm{eV}$ related to C-O 
bonds that reconfirm the presence of bicarbonates. The obtained data indicate that the sensitivity of the ISE- $\mathrm{HCO}_{3}{ }^{-}$electrodes is a mixed one and can be ascribed to both bicarbonate and carbonate ions.

a)

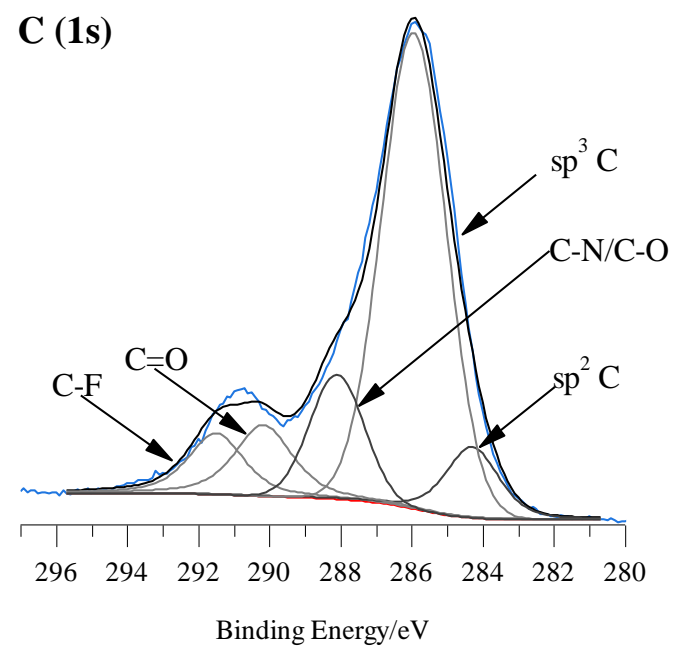

c)

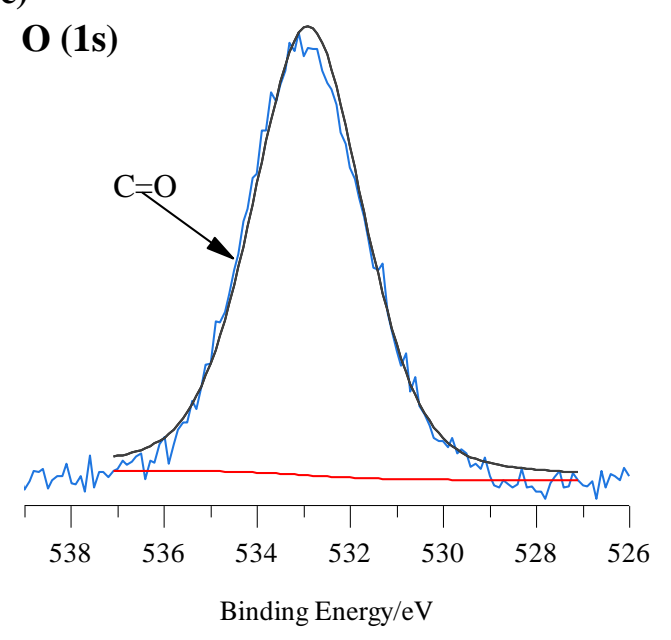

b)

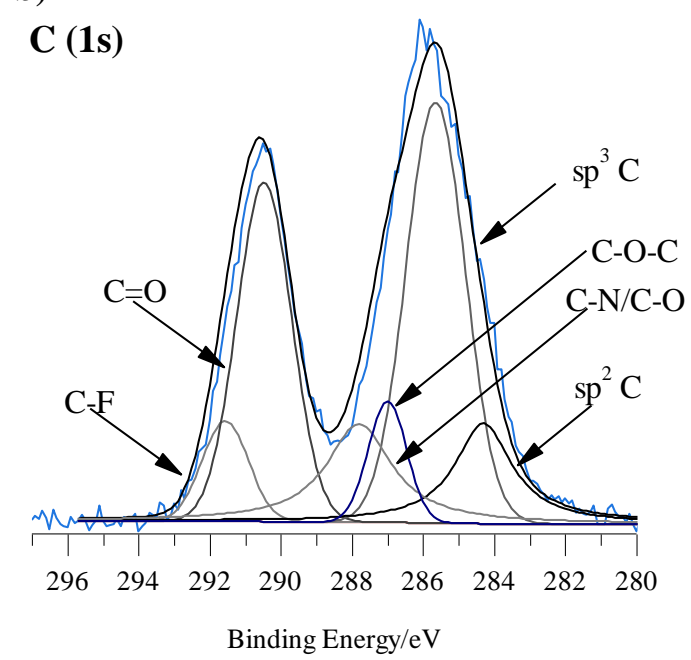

d)

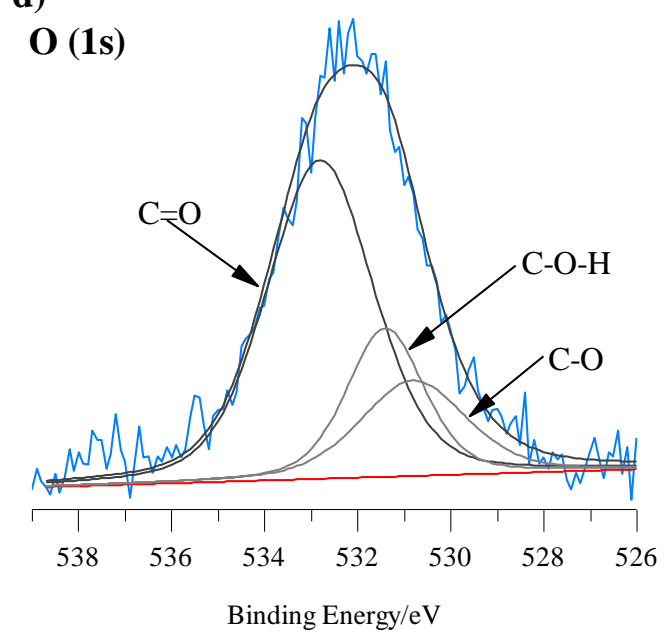

Figure 3. High-resolution XPS spectra of $\mathrm{C}(1 \mathrm{~s})$ and $\mathrm{O}(1 \mathrm{~s})$ recorded for non-conditioned membrane $(\mathbf{a}, \mathbf{c})$ and membrane conditioned in $0.1 \mathrm{~mol} \mathrm{~L}^{-1} \mathrm{NaHCO}_{3}(\mathbf{b}, \mathbf{d})$.

In order to determine whether the sensitivity of the electrode with polystyrene anion-exchange membrane is directly dictated by the $\mathrm{HCO}_{3}{ }^{-}$ion, in contrast to possible indirect mechanism by $\mathrm{CO}_{3}{ }^{2}$, a specially dedicated potentiometric measurement (experimentum crucis) was made. In accordance with the method described by Lewenstam et al. [19], the potential change $\Delta \mathrm{E}$ of ion-selective electrodes was measured first in $25 \mathrm{mmol} \mathrm{L}^{-1}$ sodium bicarbonate solution and then in $25 \mathrm{mmol} \mathrm{L}^{-1} \mathrm{NaHCO}_{3}$ solution mixed in 1/1 volume ratio with HEPES solution, 4-(2-hydroxyethyl)-1-piperazineethanesulfonic acid), at a concentration of $0.008 \mathrm{~mol} \mathrm{~L}^{-1}$. HEPES buffer solution addition, along with the change in $\mathrm{pH}$, changes the concentration ratio of $\mathrm{CO}_{3}{ }^{2-} / \mathrm{HCO}_{3}{ }^{-}$forms.

In the calculation of the theoretical potential change, $\Delta \mathrm{E}$, two cases are considered: when the electrode would show sensitivity only to carbonate ions:

$$
\Delta E_{\mathrm{CO}_{3}^{2-}}=-2.303 \frac{R T}{2 F} \log \frac{a_{\mathrm{CO}_{3}^{2-}(L)}}{a_{\mathrm{CO}_{3}^{2-}(H)}}=38.2 \mathrm{mV}
$$

or only to bicarbonate ions: 


$$
\Delta E_{\mathrm{HCO}_{3}^{-}}=-2.303 \frac{R T}{F} \log \frac{a_{\mathrm{HCO}_{3}^{-}(L)}}{a_{\mathrm{HCO}_{3}^{-}(\mathrm{H})}}=19.1 \mathrm{mV}
$$

$a_{(H)}, a_{(L)}$-is the activity of the ion in solution containing $25 \mathrm{mmol} \mathrm{L}^{-1} \mathrm{NaHCO}_{3}$ and solution with HEPES respectively.

The ion activities were calculated from the following formulas:

$$
\begin{aligned}
& a_{\mathrm{HCO}_{3}^{-}}=\frac{K_{1} C_{T} a_{H^{+}}}{\left(a_{H^{+}}\right)^{2}+K_{1} a_{H^{+}}+K_{1} K_{2}} \\
& a_{\mathrm{CO}_{3}^{2-}}=\frac{K_{1} K_{2} C_{T}}{\left(a_{H^{+}}\right)^{2}+K_{1} a_{H^{+}}+K_{1} K_{2}}
\end{aligned}
$$

where: $\mathrm{K}_{1}\left(\mathrm{pK}_{1}=6.35\right)$ and $\mathrm{K}_{2}\left(\mathrm{pK}_{2}=10.33\right)$-dissociation constants of carbonic acid at a temperature of $25{ }^{\circ} \mathrm{C}$ [20], $a_{H^{+}}$-activity of the hydrogen ion, $C_{T}$-total concentration of $\mathrm{NaHCO}_{3}$. Activity coefficients were calculated using the Debye-Hückel equation. The measured $\mathrm{pH}$ values were used in the calculations.

The measured value of $\Delta \mathrm{E}$ for the ion selective electrode with polystyrene membrane was $18.7 \pm$ $0.2 \mathrm{mV}$. Comparing this experimentally determined $\Delta \mathrm{E}$ with the theoretical prediction, it is evident that the electrodes exhibit sensitivity to bicarbonate ions. The charge transfer and membrane transport of these ions determine the response of the electrode, not the carbonate ions. Only under such circumstances, can bicarbonates be the main ions.

\subsection{Electrode Response and Selectivity}

To check the response of the electrodes the calibrations in $10^{-6}-5 \cdot 10^{-1} \mathrm{~mol} \mathrm{~L}^{-1}$ of $\mathrm{NaHCO}_{3}$ were performed. A close-to-Nernstian response slope of $-58 \pm 2 \mathrm{mV} / \log a_{\mathrm{HCO}_{3}^{-}}$was found for bicarbonate in the linear part of the calibration curve $\left(5 \cdot 10^{-4}-5 \cdot 10^{-1} \mathrm{~mol} \mathrm{~L}-1\right)$. The value of detection limit was $(1.4 \pm 0.3) \cdot 10^{-4} \mathrm{~mol} \mathrm{~L}^{-1}$. The limit of detection was determined from the intersection of the two linear segments of the calibration plot. The response time is shown in the insert in Figure 4. Each measurement was performed with three replicate electrodes and the average values with standard deviations were reported.

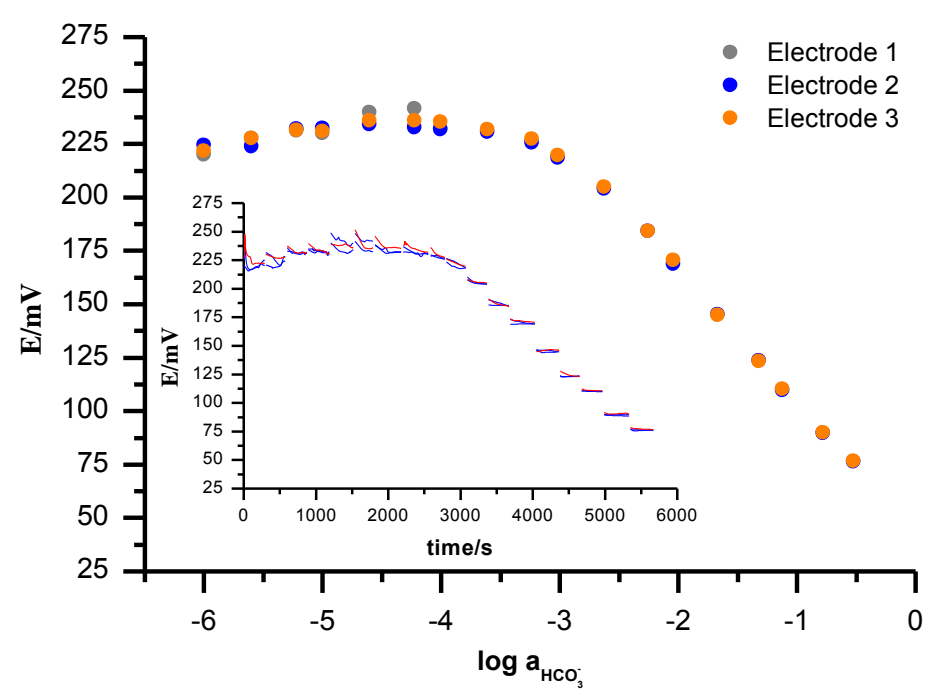

Figure 4. Potentiometric calibration curve and potential change over time (insert) of bicarbonate sensitive electrodes $(n=3)$ with a polymer matrix of divinylbenzene cross-linked polystyrene obtained during measurements in $\mathrm{NaHCO}_{3}$ solutions in the concentration range $10^{-6}-5 \cdot 10^{-1} \mathrm{~mol} \mathrm{~L}^{-1}$. 
Short-term stability can be obtained from Figure 4 . The drift $E$ over time is $0.1 \mathrm{mV} \mathrm{min}^{-1}$ for the polystyrene anion exchanger membrane. During calibration, a fast stabilization time of the signal was observed after the change of the main ion concentration; the response time $t_{90}$ is less than $5 \mathrm{~s}$. These very good dynamic properties of the bicarbonate electrode are crucial for analytical application as described later below. The lifetime of this electrode was about 2 months. During this time, the slope of the bicarbonate-sensitive electrode remained approximately stable. The effect of $\mathrm{pH}$ on electrode response in the $\mathrm{pH}$ range from 6.9 to 8.2 was purposely investigated. This range was dictated by practical application since it covers the $\mathrm{pH}$ range in the samples we used. The potential changes were measured in (a) $0.001 \mathrm{~mol} \mathrm{~L}^{-1} \mathrm{Na}_{2} \mathrm{SO}_{4}$, (b) HEPES solutions at $0.001 \mathrm{~mol} \mathrm{~L}^{-1}$. The $\mathrm{pH}$ was changed by adding $\mathrm{NaOH}$ solution. The electrodes with a polystyrene membrane are not sensitive to $\mathrm{pH}$ change, as shown in Figure 5.

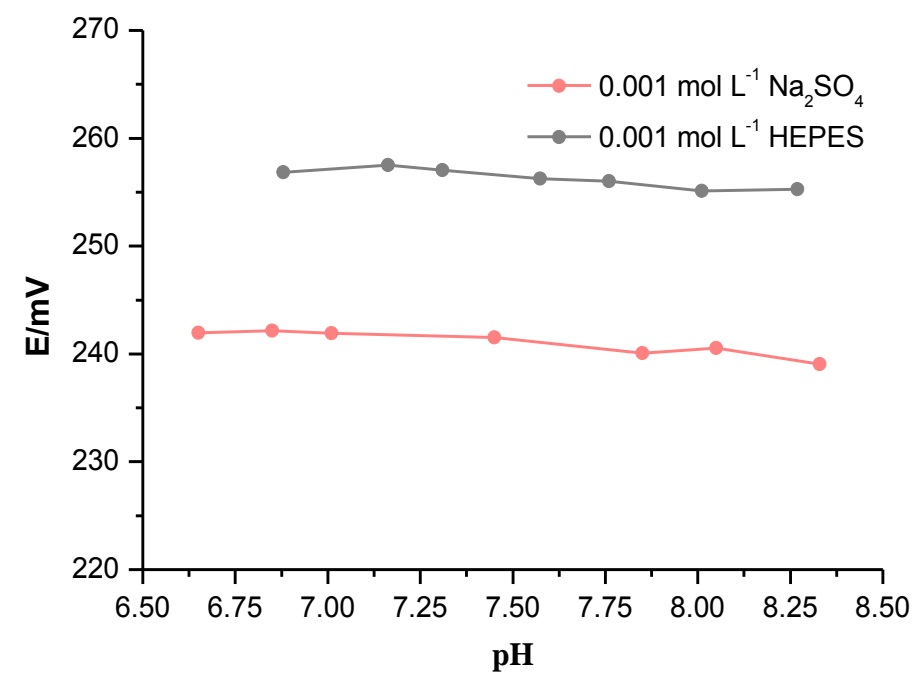

Figure 5. Effect of $\mathrm{pH}$ on the response of the potentiometric bicarbonate electrodes. The measurements were performed in HEPES buffer solution or $\mathrm{Na}_{2} \mathrm{SO}_{4}$. $\mathrm{NaOH}$ was used to change the $\mathrm{pH}$.

The selectivity coefficients measured by the two methods (SSM and FMP) and comparison of the selectivity coefficient determined by the SSM method of hydrogencarbonate ion-selective electrodes with a different polymer diaphragm matrix are presented in Table 2.

Table 2. Potentiometric selectivity coefficients determined by FPM and SSM method.

\begin{tabular}{|c|c|c|c|}
\hline \multirow{3}{*}{ Interfering ion } & \multicolumn{2}{|c|}{ Polystyrene Membrane } & \multirow{2}{*}{$\begin{array}{c}\text { PVC Membrane } \\
\log K_{\mathrm{HCO}_{3}^{-}, j}^{\text {pot }}\end{array}$} \\
\hline & \multicolumn{2}{|c|}{$\log K_{\mathrm{HCO}_{3}^{-}, j}^{p o t}$} & \\
\hline & FPM & SSM & SSM \\
\hline $\mathrm{SO}_{4}^{2-}$ & $-0.44 \pm 0.01$ & $-0.33 \pm 0.08$ & $0.72 \pm 0.05$ \\
\hline $\mathrm{Cl}^{-}$ & $0.65 \pm 0.01$ & $0.48 \pm 0.01$ & $1.08 \pm 0.02$ \\
\hline $\mathrm{Br}^{-}$ & $0.65 \pm 0.01$ & $0.60 \pm 0.05$ & $2.45 \pm 0.02$ \\
\hline
\end{tabular}

Similar selectivity coefficients were determined by both the SSM and the FPM methods. Table 2 compares the SSM selectivity coefficients for both the presently used and PVC membrane [16]. The influence of strongly interfering lipophilic chloride and bromide ions as well as divalent sulphides is, in the case of the ion-exchange membrane, much weaker than in the case of the polymeric PVC-based membranes reported before [16]. This observation is of crucial importance in the field of ISE technology.

The better selectivity for strongly interfering lipophilic anions, in our case chlorides and bromides vs. bicarbonates, can be ascribed to the chemical properties and the structure of the anion-exchange membrane used. The membrane is characterized by high ion-exchange capacity, and its 3D structure 
is made of nanopore/capillary channels "dispersed" in a bulk phase $[17,18,21-23]$. The transport of ions in such membranes can occur through solvent-filled nanopores/capillaries and the passive partition/diffusion of ions in the polystyrene phase. Immobile quaternary cation sites, available for counter ions (e.g., $\mathrm{HCO}_{3}{ }^{-}$), are present in a high number in the membrane. The ion-exchange process, initiated after contact of the membrane with bathing solution, spreads into the membrane bulk. The overall membrane selectivity results from a synergistic/collective effect of the ions permeating the membrane (through the channels and due to ion-partition in the polystyrene matrix) and the coulombic interaction between quaternary ammonium sites at the surface and in the membrane phase. The interfering chloride ions invited from a bathing solution have to substitute the main bicarbonate ions present in the membrane to exert an interfering effect. This happens in the course of a dynamic, time-dependent equilibration process, which influences the selectivity coefficients measured. The mechanism is theoretically interpreted by a diffusion layer model (DLM), which was introduced [24] and reviewed more recently by Lewenstam [25].

In general, the DLM states that the selectivity of the membranes' $K_{i, j}^{p o t}$ variability is manifested in the range set by transport parameters (kinetic discrimination) and thermodynamic parameters (true, unbiased selectivity). The DLM predicts that kinetic discrimination effects should be pronounced for the membranes with high ion-exchange capacity, equivalent to high site number [26], in particular for anion-exchange membranes [27]. According to the DLM, the selectivity coefficient in our case is represented by the ratio of transport parameters, e.g., ion mobilities or diffusion coefficients of the interfering to main ion and is $\frac{D_{\mathrm{Cl}^{-}}}{D_{\mathrm{HCO}_{3}^{-}}}=1$.7. Indeed, as shown below, a very close value $\mathrm{K}_{\mathrm{HCO}_{3}^{-}, \mathrm{Cl}^{-}}^{\text {pot }} \approx$ 1.3 was determined, which indicates that a strong ion interference is indeed suppressed by kinetic discrimination. The true (thermodynamic) selectivity, given by a product of ion mobility ratio and ion-exchange constant (ion permeation ratio), is of $10^{1}-10^{2}$ times higher $[28,29]$. The properties of the polystyrene matrix favour the kinetic discrimination process in comparison to PVC membranes.

\subsection{Determination of Bicarbonates in Samples by Simplex Method}

The membrane studied in our present research allowed taking advantage of concurrently improved selectivity via: (1) a new membrane matrix and (2) the kinetic discrimination effect.

A kinetic discrimination by definition necessitates optimizing the measurement time to get the best analytical results. Herein the optimization is achieved by the simplex method [30]. The principle of the simplex optimization is the displacement of an initial design (geometric figure) through the region studied in order to avoid experimental regions with undesirable responses. The initial geometric figure comprises $k+1$ vertex, where $k$ equals the number of variables in a $k$-dimensional domain. Therefore, the simplex in one dimensional (for one variable) is represented by a line and in three dimensional, by the tetrahedron (three variables). The simplex displacement is carried out by the reflection of the experimental point showing the worst response generating a new simplex that should be once again analyzed and displaced to the optimal region.

Figure 6 shows the simplex method with regard to the optimization of three variables through the displacement of the initial simplex represented by the geometric figure. First, in order to optimize the measurement time, the calibration was carried out in sodium bicarbonate solutions and then in the sample containing interfering ions (chlorides) at different time periods, starting at $65 \mathrm{~s}$ for a readout time and decreasing to $2.5 \mathrm{~s}$. Calibration was carried out in solutions with the following concentrations: $10^{-3}, 5 \times 10^{-3}, 10^{-2}, 5 \times 10^{-2}, 10^{-1} \mathrm{~mol} \mathrm{~L}^{-1} \mathrm{NaHCO}_{3}$, and in the sample of $25 \mathrm{mmol} \mathrm{L}^{-1} \mathrm{NaHCO}_{3}$ and $0.1 \mathrm{~mol} \mathrm{~L}^{-1} \mathrm{NaCl}$ which was used to estimate deviation from the target bicarbonate sample concentration, $25 \mathrm{mmol} \mathrm{L}^{-1}$ and corresponding activity 19.5. The measured apparent activity of bicarbonate ions in the sample was calculated using Equation (1) for $\mathrm{S}=58,3 \mathrm{mV} / \log a_{\mathrm{HCO}_{3}^{-}}$and $\mathrm{K}=3$. Although still far the target the closest, and reproducible $(\mathrm{n}=3)$ readout was found after $5 \mathrm{~s}$ (Figure 7). Error bars are standard deviations obtained for measurements with three bicarbonate ion-selective electrodes. 


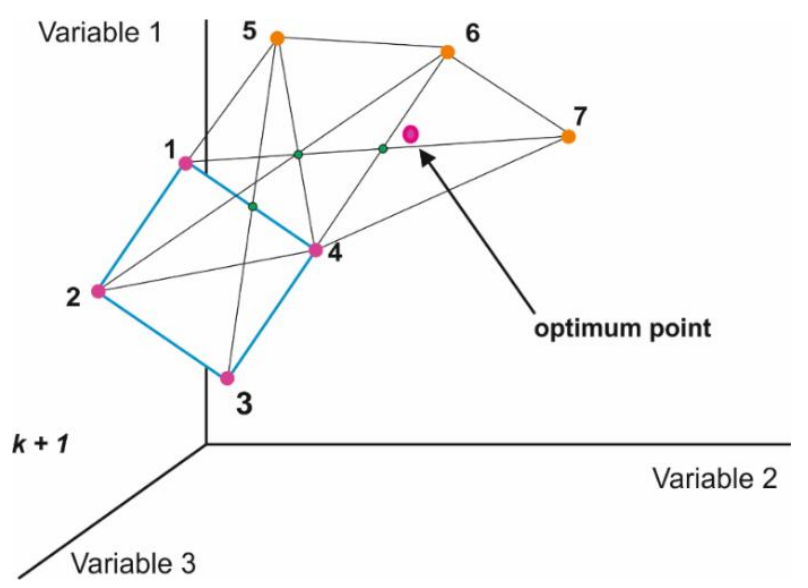

Figure 6. Example of the displacement of initial simplex to the region of optimum response of three variables.

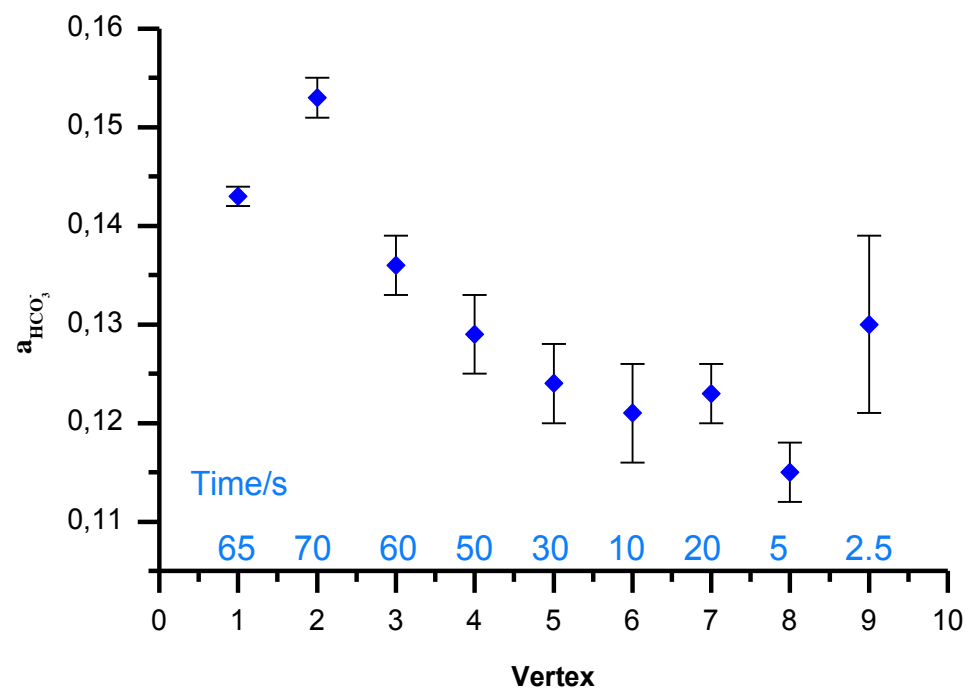

Figure 7. Minimizing the influence of chloride ion by the optimization of readout time in simplex measurements; the sample contains $25 \mathrm{mmol} \mathrm{L}^{-1} \mathrm{NaHCO}_{3}$ and $0.1 \mathrm{~mol} \mathrm{~L}^{-1} \mathrm{NaCl}$. The bars represent standard deviation for three identical electrodes.

Obviously in such a case, the discrimination of interfering chloride ions is due to kinetic discrimination.

After the optimal time of measurement time was found, multi-dimensional calibration and simplex optimization were performed.

The response of the ion selective electrode to primary ion (bicarbonate) and interferents (chloride ion) is described by the Nikolskii-Eisenman equation:

$$
E=E^{0}+S \log \left(a_{\mathrm{HCO}_{3}^{-}}+K_{\mathrm{HCO}_{3}^{-}, \mathrm{Cl}^{-}}^{\text {pot }} \cdot a_{\mathrm{Cl}^{-}}\right)
$$

where $E^{0}$ is the standard potential, $S$ is the slope of the linear part of the calibration curve, $\mathrm{K}_{\mathrm{HCO}_{3}^{-}, \mathrm{Cl}^{-}}^{\mathrm{pot}}$ is the selectivity coefficient.

The reason for applying of the multi-dimensional calibration and simplex optimization is in the apparent interdependence of selectivity, formal potential, and slope in the Nikolskii-Eisenman equation. In the presence of interferents the slope of the characteristics of the bicarbonate electrode $S$ and the value of $E^{0}$ may change, which can lead to significant errors in the analysis that need to be circumvented. In conventional potentiometry with ISEs the value of $E^{0} S$, and selectivity coefficients are 
determined prior to the sample measurements and assumed to be applicable in sample measurements. Such methodology presents the risk of inadequate use of the Nikolskii-Eisenman equation parameters and error in determination of the sample analyte. The simplex method allows concurrent optimizing

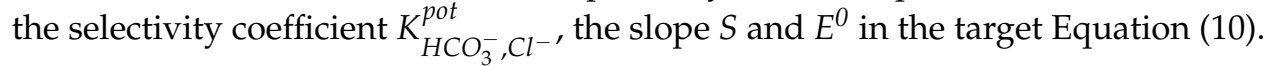

The measurements were thus carried out at three concentration levels of $\mathrm{HCO}_{3}{ }^{-}$and $\mathrm{Cl}^{-}$in the range of $10^{-3}-10^{-1} \mathrm{~mol} \mathrm{~L}^{-1}$ in two measuring series (solutions 1.1-1.3 and 2.1-2.3). The concentration of $\mathrm{HCO}_{3}{ }^{-}$and $\mathrm{Cl}^{-}$ions in the calibration solutions are summarized in Table 3. Three identical ion-selective bicarbonate electrodes were used for the measurements; the measurement time in each solution was $5 \mathrm{~s}$. In all measuring series, the measurements were repeated five times.

Table 3. Concentrations of ions in calibration solutions.

\begin{tabular}{cccccc}
\hline & Series $\mathbf{1}$ & \multicolumn{3}{c}{ Series 2 } \\
\hline No & $\begin{array}{c}\mathbf{H C O}_{3}^{-} \\
{\left[\mathbf{m o l ~ L}^{-1}\right]}\end{array}$ & $\begin{array}{c}\mathrm{Cl}^{-} \\
{\left[\mathrm{mol} \mathrm{L}^{-\mathbf{1}}\right]}\end{array}$ & $\mathbf{N o}$ & $\begin{array}{c}\mathbf{H C O}_{3}^{-} \\
{\left[\mathbf{m o l ~ L}^{-1}\right]}\end{array}$ & $\begin{array}{c}\mathrm{Cl}^{-} \\
{\left[\mathbf{m o l ~ L}^{-1}\right]}\end{array}$ \\
\hline 1.1 & $10^{-1}$ & $10^{-3}$ & $\mathbf{2 . 1}$ & $10^{-3}$ & $10^{-1}$ \\
1.2 & $10^{-2}$ & $10^{-2}$ & $\mathbf{2 . 2}$ & $10^{-2}$ & $10^{-2}$ \\
1.3 & $10^{-3}$ & $10^{-1}$ & $\mathbf{2 . 3}$ & $10^{-1}$ & $10^{-3}$ \\
\hline
\end{tabular}

Next, the slope values and $E^{0}$ obtained during calibration in $\mathrm{NaHCO}_{3}$ solutions without the presence of interferents and the value of the selectivity coefficient obtained by SSM were used to determine the initial vertices. Calculations of the initial values of the vertexes are presented in Table 4 .

Table 4. The values of initial vertices of the simplex optimization.

\begin{tabular}{cccc}
\hline Vertex & $\mathbf{E}^{\mathbf{0}}[\mathbf{m V}]$ & $\mathbf{S}[\mathbf{m V / l o g} \mathbf{~ a}]$ & $\mathbf{K}_{\mathbf{H C O}_{3}^{-}, \mathrm{Cl}^{-}}^{\text {pot }}$ \\
\hline 1 & 29.3 & -58.1 & 3.02 \\
2 & $29.3+1 \cdot 0.1$ & -58.1 & 3.02 \\
3 & $29.3+0.5 \cdot 0.1$ & $-58.1+0.87 \cdot 0.1$ & 3.02 \\
4 & $29.3+0.5 \cdot 0.1$ & $-58.1+0.29 \cdot 0.1$ & $3.02+0.82 \cdot 0.1$ \\
\hline
\end{tabular}

The simplex routine varies the values of the selectivity coefficient $\mathrm{K}_{\mathrm{HCO}_{3}^{-}, \mathrm{Cl}^{-}}^{\mathrm{pot}}$, standard cell potential $\mathrm{E}^{0}$ and slope according to the rules of the simplex algorithm until the error depicted by Equation (11) is as low as possible:

$$
e r r=\sqrt{\sum\left(a_{k}^{*}-a_{k}\right)^{2} / a_{k}^{2}} / n
$$

In this equation, $a_{k}^{*}$ is the designated activity of $\mathrm{HCO}_{3}{ }^{-}, a_{k}$ is the theoretical activity of the ion, while $n$ is the number of solutions in a given series of measurements $(n=3)$. A Microsoft Excel spreadsheet was used for the calculations.

The optimized parameter values from the two measurements series which ensure the best fit between the determined main ion activity from the Nikolskii-Eisenman equation and the known target value of this ion are, respectively: $E^{0}=26.69 \pm 1.69 \mathrm{mV}, S=-58.77 \pm 0.28 \mathrm{mV} / \log$ a $\mathrm{HCO}_{3}{ }^{-}$and $\mathrm{K}_{\mathrm{HCO}_{3}^{-}, \mathrm{Cl}^{-}}^{\mathrm{pot}}=1.31 \pm 0.02$.

To prove the validity of this approach we determined the concentrations of $\mathrm{HCO}_{3}{ }^{-}$ions in samples with a known concentration of anions, and then in the real samples of mineral water. Three identical ion-selective bicarbonate electrodes were used for the measurements; the measurements were repeated three times $(n=3)$. To determine the concentration in the real sample, potentiometric titration in each sample was additionally performed. The water samples were titrated with $10^{-1} \mathrm{~mol} \mathrm{~L}^{-1} \mathrm{HCl}$ solution until $\mathrm{pH} 4$ was attained. The obtained results with standard deviation values and relative errors are summarized in Table 5. Relative error is calculated as the difference between the concentration 
measured by bicarbonate ion-selective electrode and the true concentration (the values of concentration given in Table 1) divided by the true concentration.

Table 5. Results of determination of bicarbonate ions.

\begin{tabular}{|c|c|c|c|c|c|c|}
\hline Sample & $\begin{array}{l}\text { Determined } \\
\text { Bicarbonate } \\
{\left[\mathrm{mmol} \mathrm{L}^{-1}\right]}\end{array}$ & $\begin{array}{c}\text { Relative } \\
\text { Error* }[\%]\end{array}$ & $\begin{array}{l}\text { Determined } \\
\text { Bicarbonate } \\
{\left[\mathrm{mmol} \mathrm{L}^{-1}\right]}\end{array}$ & $\begin{array}{c}\text { Relative } \\
\text { Error* [\%] }\end{array}$ & $\begin{array}{c}\text { N-E Equation } \\
\text { Relative error } \\
{[\%]}\end{array}$ & $\begin{array}{c}\text { Potentiometric } \\
\text { Titration } \\
{\left[\mathrm{mmol} \mathrm{L}^{-1}\right]}\end{array}$ \\
\hline & \multicolumn{2}{|c|}{ Simplex, 1 day } & \multicolumn{2}{|c|}{ Simplex, 10 days } & & \\
\hline 1 & $100.7 \pm 3.3$ & 0.7 & $97.7 \pm 4.0$ & 2.3 & 10.8 & \\
\hline 2 & $49.6 \pm 4.7$ & 0.8 & $50.7 \pm 3.8$ & 1.4 & 29.9 & \\
\hline 3 & $25.9 \pm 0.7$ & 3.6 & $25.5 \pm 0.1$ & 2.0 & 59.0 & - \\
\hline 4 & $100.6 \pm 1.3$ & 0.6 & $102.2 \pm 5.7$ & 2.2 & 156.5 & \\
\hline 5 & $49.3 \pm 5.2$ & 1.4 & $50.9 \pm 4.6$ & 1.8 & 217.9 & \\
\hline 6 & $23.9 \pm 4.5$ & 4.4 & $22.6 \pm 3.0$ & 9.6 & 326.2 & \\
\hline Jan & $8.5 \pm 0.9$ & 1.2 & $8.7 \pm 1.1$ & 1.2 & 20.2 & $8.3 \pm 0.3$ \\
\hline Jozef & $21.0 \pm 3.2$ & 2.3 & $21.4 \pm 2.8$ & 0.5 & 57.5 & $20.5 \pm 1.4$ \\
\hline Slotwinka & $48.2 \pm 5.6$ & 1.8 & $47.1 \pm 0.9$ & 4.1 & 5.4 & $46.0 \pm 0.7$ \\
\hline Donat $\mathrm{Mg}$ & $123.0 \pm 7.5$ & 0.9 & $123.7 \pm 0.6$ & 1.5 & 10.2 & $122.5 \pm 3.5$ \\
\hline Franciszek & $142.6 \pm 0.8$ & 2.6 & $143.8 \pm 2.5$ & 3.5 & 66.4 & $139.8 \pm 3.2$ \\
\hline Cisowianka & $8.9 \pm 0.7$ & 1.1 & $8.8 \pm 0.5$ & 0.0 & 6.9 & $8.8 \pm 0.4$ \\
\hline Staropolanka & $10.1 \pm 1.3$ & 8.6 & $10.8 \pm 0.7$ & 16.1 & 19.8 & $10.5 \pm 0.2$ \\
\hline Kryniczanka & $24.5 \pm 0.2$ & 3.9 & $23.8 \pm 0.1$ & 6.7 & 1.4 & $24.9 \pm 2.1$ \\
\hline
\end{tabular}

Optimization of the parameters in the Nikolskii-Eisenman equation allows satisfactory determination of hydrogencarbonate ions in the test sample, even in the presence of interferents at high concentrations. It is possible to determine the concentration of bicarbonate ions in the samples without the re-calculation of parameters from the Nikolskii-Eisenman equation for 10 days. After 20 days of conditioning, the relative error for all samples was about $40 \%$.

The simplex method allowed minimizing the influence of the matrix. In the conventional case while determining the analyte concentration with the sample, with the $E^{0}$ and $S$ values derived from the calibration curve and the $\mathrm{K}_{\mathrm{HCO}_{3}^{-}, \mathrm{Cl}^{-}}^{\mathrm{pot}}$ determined by the SSM method, and without optimized time the analyte concentrations are significantly overestimated (Table 5, column named N-E equation). For example, for sample No. 2 where the concentration of bicarbonates is 5 times higher than that of interferent ions, the relative error would be $+29.9 \%$ bigger, while for sample No. 6 where the interferent of the concentration is four times higher, the error would be as high as $+326.2 \%$.

Notwithstanding, both the theoretical and analytical approaches presented herein need to be further advanced. The limitation of this method is selectivity, especially for samples with the high content of interfering ions. The goal lies in finding even better membrane materials, an interpretation that would widen the transport concept (i.e., the influence of membrane porosity and tortuosity), measurement strategies and adequate analytical applications, which comprise the driving force of our ongoing research.

\section{Conclusions}

Hydrophilic anionic membrane made of divinylbenzene cross-linked polystyrene with high ion-exchange capacity is a promising material for designing a bicarbonate ion-selective electrode. The electrodes used showed a stable and fast response but much better selectivity in comparison to similar PVC-based membranes. The lesser influence of lipophilic ions can be attributed to the kinetic discrimination and a high ion-exchange capacity of the membranes used. Additionally, the membranes are insensitive to $\mathrm{pH}$ over a wide range.

The simplex method was satisfactorily employed to minimize the interference of chloride ions on the potentiometric signal. Optimization of the measurement time and parameters such as slope, standard potential and selectivity were achieved by application of the simplex method. 
The use of an appropriate polymer matrix and selection of response parameters of the electrodes made possible the determination of the hydrogencarbonate ions in the presence of chloride ions even at high concentration.

We foresee that the spreading use of novel composite and heterogenous ion-exchange electrode materials and nano-porous membranes will widen the scope of application for potentiometric sensors. Moreover, by delivering further proof of the kinetic effects in the membrane formation process, the paradigm of ion-selective electrode membranes which are treated as a single phase able to create phase boundary potential will be revised.

Author Contributions: Conceptualization, S.D. and A.L.; methodology, S.D.; software, S.D.; validation, S.D., J.M. and A.L.; formal analysis, S.D.; J.M., A.L..; investigation, S.D., J.M.; resources, S.D., J.M.; data curation, S.D.; writing—original draft preparation, S.D.; writing—review and editing, A.L.; visualization, S.D..; supervision, A.L.; project administration, A.L.; funding acquisition, A.L.

Funding: This research was funded by THE NATIONAL SCIENCE CENTRE (NCN, Poland) via research grant number 2014/15/B/ST5/02185.

Conflicts of Interest: The authors declare no conflict of interest.

\section{References}

1. Lewenstam, A. Routines and Challenges in Clinical Application of Electrochemical Ion-Sensors. Electroanalysis 2014, 26, 1171-1181. [CrossRef]

2. Grekovich, A.L.; Mikhelson, K.N. An Anomalous Behavior of Anion-Exchange Membranes with Low Concentration of Quaternary Ammonium Sites: An Apparent Selectivity to Bicarbonate and Phosphate, and Its True Nature. Electroanalysis 2002, 14, 1391-1396. [CrossRef]

3. Maj-Zurawska, M.; Sokalski, T.; Ostaszewska, J.; Paradowski, D.; Mieczkowski, J.; Czarnocki, Z.; Lewenstam, A.; Hulanicki, A. Carbonate Ion Selective Electrodes with Trifluoroacetophenone Derivatives in Potentiometric Clinical Analyser. Talanta 1997, 44, 1641-1647. [CrossRef]

4. Bobacka, J.; Maj-Zurawska, M.; Lewenstam, A. Carbonate Ion-Selective Electrode with Reduced Interference from Salicylate. Biosens. Bioelectron. 2003, 18, 245-253. [CrossRef]

5. Sokalski, T.; Paradowski, D.; Ostaszewska, J.; Maj-Żurawska, M.; Mieczkowski, J.; Lewenstam, A.; Hulanicki, A. Observations on the Behaviour of Some Trifluoroacetophenone Derivatives as Neutral Carriers for Carbonate Ion-Selective Electrodes. Analyst 1996, 121, 133-138. [CrossRef]

6. Levitchev, S.; Smirnova, A.; Khitrova, V.; Lvova, L.; Bratov, A.; Vlasov, Y. Photocurable Carbonate-Selective Membranes for Chemical Sensors Containing Lipophilic Additives. Sens. Actuators B Chem. 1997, 44, $397-401$. [CrossRef]

7. Xie, X.; Bakker, E. Non-Severinghaus Potentiometric Dissolved $\mathrm{CO}_{2}$ Sensor with Improved Characteristics. Anal. Chem. 2013, 85, 1332-1336. [CrossRef] [PubMed]

8. Zhan, N.; Huang, Y.; Rao, Z.; Zhao, X.-L. Fast Detection of Carbonate and Bicarbonate in Groundwater and Lake Water by Coupled Ion Selective Electrode. Chin. J. Anal. Chem. 2016, 44, 355-360. [CrossRef]

9. Mikhelson, K.N. Ion-Selective Electrodes; Lecture notes in chemistry; Springer: Berlin, Germany, 2013.

10. Park, E.R.; Chung, Y.J.; Hwang, S.W.; Heo, M.; Chae, Y.J.; Kim, H.S.; Lee, S.W.; Shin, J.H.; Kim, I.T.; Kwan, G.-C.; et al. All-Solid-State Ion-Selective Silicone Rubber Membrane Electrodes with a New Conducting Polymer. J. Korean Phys. Soc. 2012, 60, 925-928. [CrossRef]

11. Cha, M.J.; Shin, J.H.; Oh, B.K.; Kim, C.Y.; Cha, G.S.; Shin, D.S.; Kim, B. Asymmetric Cellulose Acetate Membrane-Based Carbonate- and Chloride-Selective Electrodes. Anal. Chim. Acta 1995, 315, 311-319. [CrossRef]

12. Sakong, D.S.; Cha, M.J.; Shin, J.H.; Cha, G.S.; Ryu, M.S.; Hower, R.W.; Brown, R.B. Asymmetric MembraneBased Potentiometric Solid-State Ion Sensors. Sens. Actuators B Chem. 1996, 32, 161-166. [CrossRef]

13. Moulay, S. Chemical Modification of Poly(Vinyl Chloride)—Still on the Run. Prog. Polym. Sci. 2010, 35, 303-331. [CrossRef]

14. Górski, Ł.; Malinowska, E. Fluoride-Selective Sensors Based on Polyurethane Membranes Doped with Zr(IV)-Porphyrins. Anal. Chim. Acta 2005, 540, 159-165. [CrossRef] 
15. González-Bellavista, A.; Macanás, J.; Muñoz, M.; Fabregas, E. Sulfonated Poly(Ether Ether Ketone) as an Alternative Charged Material to Poly(Vinyl Chloride) in the Design of Ion-Selective Electrodes. Anal. Chim. Acta 2006, 577, 85-90. [CrossRef]

16. Dabrowska, S.; Migdalski, J.; Lewenstam, A. Direct Potentiometric Determination of Hydrogen Carbonate in Mineral Waters. Electroanalysis 2017, 29, 140-145. [CrossRef]

17. Varcoe, J.R.; Atanassov, P.; Dekel, D.R.; Herring, A.M.; Hickner, M.A.; Kohl, P.A.; Kucernak, A.R.; Mustain, W.E.; Nijmeijer, K.; Scott, K.; et al. Anion-Exchange Membranes in Electrochemical Energy Systems. Energy Environ. Sci. 2014, 7, 3135-3191. [CrossRef]

18. Hickner, M.A. Strategies for Developing New Anion Exchange Membranes and Electrode Ionomers. Electrochem. Soc. Interface 2017, 26, 69-73. [CrossRef]

19. Lewenstam, A.; Ivaska, A.; Wänninen, E. Single-Point Titration of Metal Ions and Ligands by Measuring Change in pH. Talanta 1986, 33, 739-742. [CrossRef]

20. Kortlever, R.; Tan, K.H.; Kwon, Y.; Koper, M.T.M. Electrochemical Carbon Dioxide and Bicarbonate Reduction on Copper in Weakly Alkaline Media. J. Solid State Electrochem. 2013, 17, 1843-1849. [CrossRef]

21. Encyclopedia of Life Support Systems (Eolss): V.1: Desalination and Water Resources (Desware): Membrane Processes; EOLSS Publishers Co., Ltd.: Oxford, UK, 2010.

22. Li, N.; Guiver, M.D. Ion Transport by Nanochannels in Ion-Containing Aromatic Copolymers. Macromolecules 2014, 47, 2175-2198. [CrossRef]

23. Koter, S. Transport of Simple Electrolyte Solutions through Ion-Exchange Membranes-The Capillary Model. J. Membr. Sci. 2002, 206, 201-215. [CrossRef]

24. Hulanicki, A.; Lewenstam, A. Interpretation of Selectivity Coefficients of Solid-State Ion-Selective Electrodes by Means of the Diffusion-Layer Model. Talanta 1977, 24, 171-175. [CrossRef]

25. Lewenstam, A. Non-Equilibrium Potentiometry-The Very Essence. J. Solid State Electrochem. 2011, 15, 15-22. [CrossRef]

26. Karas, F.; Hnát, J.; Paidar, M.; Schauer, J.; Bouzek, K. Determination of the Ion-Exchange Capacity of Anion-Selective Membranes. Int. J. Hydrogen Energy 2014, 39, 5054-5062. [CrossRef]

27. Morf, W.E. The Principles of Ion-Selective Electrodes and of Membrane Transport; Elsevier Science: Burlington, NJ, USA, 2012.

28. Sata, T. Studies on Anion Exchange Membranes Having Permselectivity for Specific Anions in Electrodialysis-Effect of Hydrophilicity of Anion Exchange Membranes on Permselectivity of Anions. J. Membr. Sci. 2000, 167, 1-31. [CrossRef]

29. Amel, A.; Gavish, N.; Zhu, L.; Dekel, D.R.; Hickner, M.A.; Ein-Eli, Y. Bicarbonate and Chloride Anion Transport in Anion Exchange Membranes. J. Membr. Sci. 2016, 514, 125-134. [CrossRef]

30. Bezerra, M.A.; dos Santos, Q.O.; Santos, A.G.; Novaes, C.G.; Ferreira, S.L.C.; de Souza, V.S. Simplex Optimization: A Tutorial Approach and Recent Applications in Analytical Chemistry. Microchem. J. 2016, 124, 45-54. [CrossRef]

(C) 2019 by the authors. Licensee MDPI, Basel, Switzerland. This article is an open access article distributed under the terms and conditions of the Creative Commons Attribution (CC BY) license (http:/ / creativecommons.org/licenses/by/4.0/). 